\title{
Altered molecular signatures during kidney development after intrauterine growth restriction of different origins
}

\author{
Eva Nüsken ${ }^{1}$ (D) Gregor Fink $^{1}$ (I) $\cdot$ Felix Lechner ${ }^{1} \cdot$ Jenny Voggel ${ }^{1}$ (D) $\cdot$ Maria Wohlfarth ${ }^{1} \cdot$ Lisa Sprenger $^{1}$. \\ Nava Mehdiani ${ }^{1} \cdot$ Lutz T. Weber $^{1} \cdot$ Max Christoph Liebau ${ }^{1,2} \cdot$ Bent Brachvogel $^{1,3} \cdot$ Jörg Dötsch $^{1}$ • \\ Kai-Dietrich Nüsken ${ }^{1}$
}

Received: 27 June 2019 / Revised: 16 December 2019 / Accepted: 7 January 2020 / Published online: 1 February 2020

(C) The Author(s) 2020

\begin{abstract}
This study was performed to identify transcriptional alterations in male intrauterine growth restricted (IUGR) rats during and at the end of nephrogenesis in order to generate hypotheses which molecular mechanisms contribute to adverse kidney programming. IUGR was induced by low protein (LP) diet throughout pregnancy, bilateral uterine vessel ligation (LIG), or intrauterine stress (IUS) by sham operation. Offspring of unimpaired dams served as controls. Significant acute kidney damage was ruled out by negative results for proteins indicative of ER-stress, autophagy, apoptosis, or infiltration with macrophages. Renal gene expression was examined by transcriptome microarrays, demonstrating 53 (LP, $n=12$; LIG, $n=32$; IUS, $n=9$ ) and 134 (LP, $n=10$; LIG, $n=41$; IUS, $n=83$ ) differentially expressed transcripts on postnatal days (PND) 1 and 7, respectively. Reduced Pilra (all IUGR groups, PND 7), Nupr1 (LP and LIG, PND 7), and Kap (LIG, PND 1) as well as increased Ccl20, S100a8/a9 (LIG, PND 1), Ifna4, and Ltb4r2 (IUS, PND 7) indicated that inflammation-related molecular dysregulation could be a "common" feature after IUGR of different origins. Network analyses of transcripts and predicted upstream regulators hinted at proinflammatory adaptions mainly in LIG (arachidonic acid-binding, neutrophil aggregation, toll-like-receptor, NF-kappa B, and TNF signaling) and dysregulation of AMPK and PPAR signaling in LP pups. The latter may increase susceptibility towards obesity-associated kidney damage. Western blots of the most prominent predicted upstream regulators confirmed significant dysregulation of RICTOR in LP (PND 7) and LIG pups (PND 1), suggesting that mTORrelated processes could further modulate kidney programming in these groups of IUGR pups.
\end{abstract}

\section{Key messages}

- Inflammation-related transcripts are dysregulated in neonatal IUGR rat kidneys.

- Upstream analyses indicate renal metabolic dysregulation after low protein diet.

- RICTOR is dysregulated after low protein diet and uterine vessel ligation.

Keywords Developmentalkidney programming $\cdot$ Inflammation $\cdot$ Intrauterine growth restriction (IUGR) $\cdot$ Lipid metabolism $\cdot$ Low protein diet $\cdot$ Uterine vessel ligation

Electronic supplementary material The online version of this article (https://doi.org/10.1007/s00109-020-01875-1) contains supplementary material, which is available to authorized users.

Kai-Dietrich Nüsken

kai-dietrich.nuesken@uk-koeln.de

1 Department of Pediatrics and Adolescent Medicine, University of Cologne, Medical Faculty and University Hospital Cologne, Cologne, Germany
2 Department II of Internal Medicine and Center for Molecular Medicine Cologne, University of Cologne, Faculty of Medicine and University Hospital Cologne, Cologne, Germany

3 Center for Biochemistry, University of Cologne, Medical Faculty and University Hospital Cologne, Cologne, Germany 


\section{Introduction}

Adverse environmental conditions during intrauterine and early postnatal life have been linked to the predisposition for noncommunicable diseases in later life [1]. Low birth weight is highly prevalent and affects almost $15 \%$ of newborn children worldwide [2,3]. Insufficient intrauterine nutrient supply induces intrauterine growth restriction (IUGR) and is a major cause of low birth weight $[1,2,4,5]$. Concerning renal outcome, IUGR may predispose to an unfavorable course of glomerulopathies, arterial hypertension, and decreased renal function and an elevated risk of end-stage renal disease in young adulthood [6-12].

The developing kidney is particularly susceptible to adverse environmental impacts since even small changes in gene or protein expression during critical time spans may lead to severely altered renal outcome [13]. In humans, urine is first produced after 10 weeks of gestation and nephrogenesis is completed by the 36 th postconceptional week [12]. Further growth and maturation of cortical and medullary structures take place in late pregnancy and the first months of life [14]. In rats, nephrogenesis continues until postnatal day (PND) 8 [15]. Rat kidney development in the first postnatal week of life therefore corresponds to human renal development in the third trimester.

Various experimental models of IUGR have been developed to elucidate the molecular links between insufficient intrauterine conditions and programming of adverse renal outcome. The rat models of low protein (LP) diet throughout pregnancy or bilateral ligation (LIG) of the uterine vessels during terminal pregnancy have been most widely used since they were designed to represent the most common causes of IUGR in humans, namely either malnutrition or placental insufficiency [5, 16-20]. Previous studies reported decreased nephron numbers and varying results concerning glomerular size, glomerular filtration rate, blood pressure, or proteinuria after both insults [18, 21-23]. An aggravated course of experimental glomerulonephritis was reported both after LP and LIG $[19,24]$. As the insults reflect two pathophysiologically different situations concerning both timing and type of intrauterine insufficiency, molecular mechanisms of early renal programming probably differ [16]. However, there is no comparison of the insults concerning molecular alterations during nephrogenesis so far. Ideally, identification of alterations could offer the opportunity for a common approach to ameliorate kidney diseases after IUGR of different origins.

This study was performed to identify molecular alterations and predict dysregulated functional networks in male rat pups during (PND 1) and at the end of nephrogenesis (PND 7) to generate hypotheses which mechanisms may contribute to adverse developmental kidney programming after IUGR of different origins. We focused on the identification of common mechanisms first, followed by the analysis of model-specific alterations. Since not only LIG and LP but also intrauterine stress (IUS) induced by sham operation results in moderate IUGR and programming, we included IUS pups as a third experimental group [25]. All experimental groups were compared with unimpaired controls.

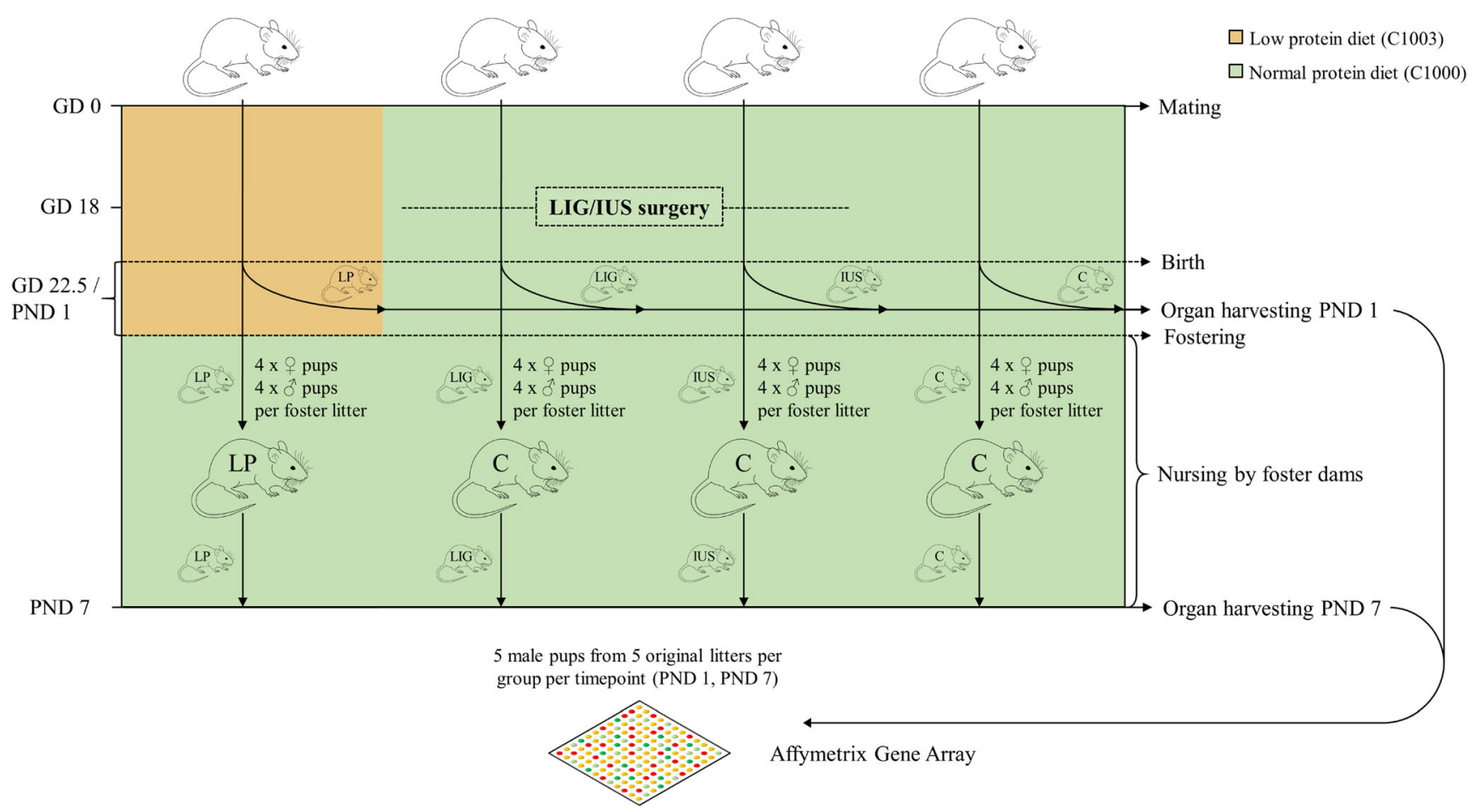

Fig. 1 Experimental design is shown. For further details see text or Supplemental File 1 
Fig. 2 Weight data of all male pups from the animal experiments are shown. Transcriptome analyses were performed in only 5 animals per group, remaining pups were used for other studies. a Birth weight $(\mathrm{g})$ in $\mathrm{C}(n=105)$, LP $(n=70)$, LIG $(n=52$ small), and IUS $(n=99)$ pups. b

Bodyweight (g) on postnatal day (PND) 7 in C, $(n=24), \mathrm{LP},(n=$ $16)$, LIG $(n=14)$, and IUS $(n=$ 17) pups. c Absolute kidney weight and e kidney weight/body weight ratio of both kidneys of animals dissected on PND 1 in C $(n=27)$, LP $(n=17)$, LIG $(n=$ $21)$, and IUS ( $n=24)$ pups. $\mathbf{d}$ Absolute kidney weight and $\mathbf{f}$ kidney weight/body weight ratio of both kidneys of animals dissected on PND 7 (for numbers see legend to Fig. 2b). Significances are shown by asterisks for the comparisons $\mathrm{LP}-\mathrm{C}$, $\mathrm{LIG}-\mathrm{C}$, and IUS-C above the respective bar; $* p<0.05$;** $p<0.01$;

$* * * p<0.001$ (all $p$ values

Bonferroni adjusted). Further comparisons with significant results: a LP-LIG, *; LIG-IUS, ***; b none; c LP-IUS, *; LIGIUS, *; d LP-IUS, *; e LP-IUS, $* ; \mathbf{f}$ none
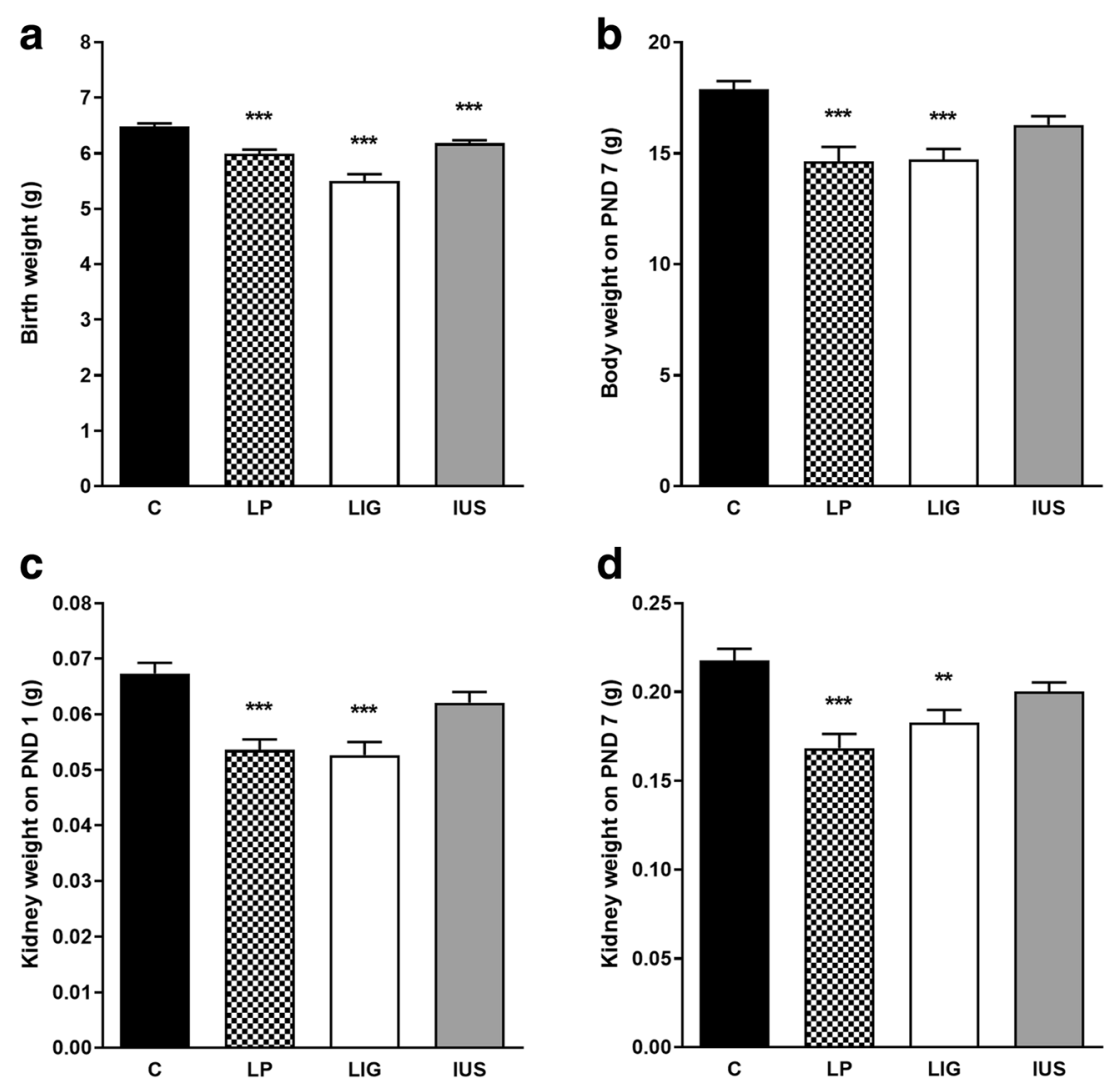

d
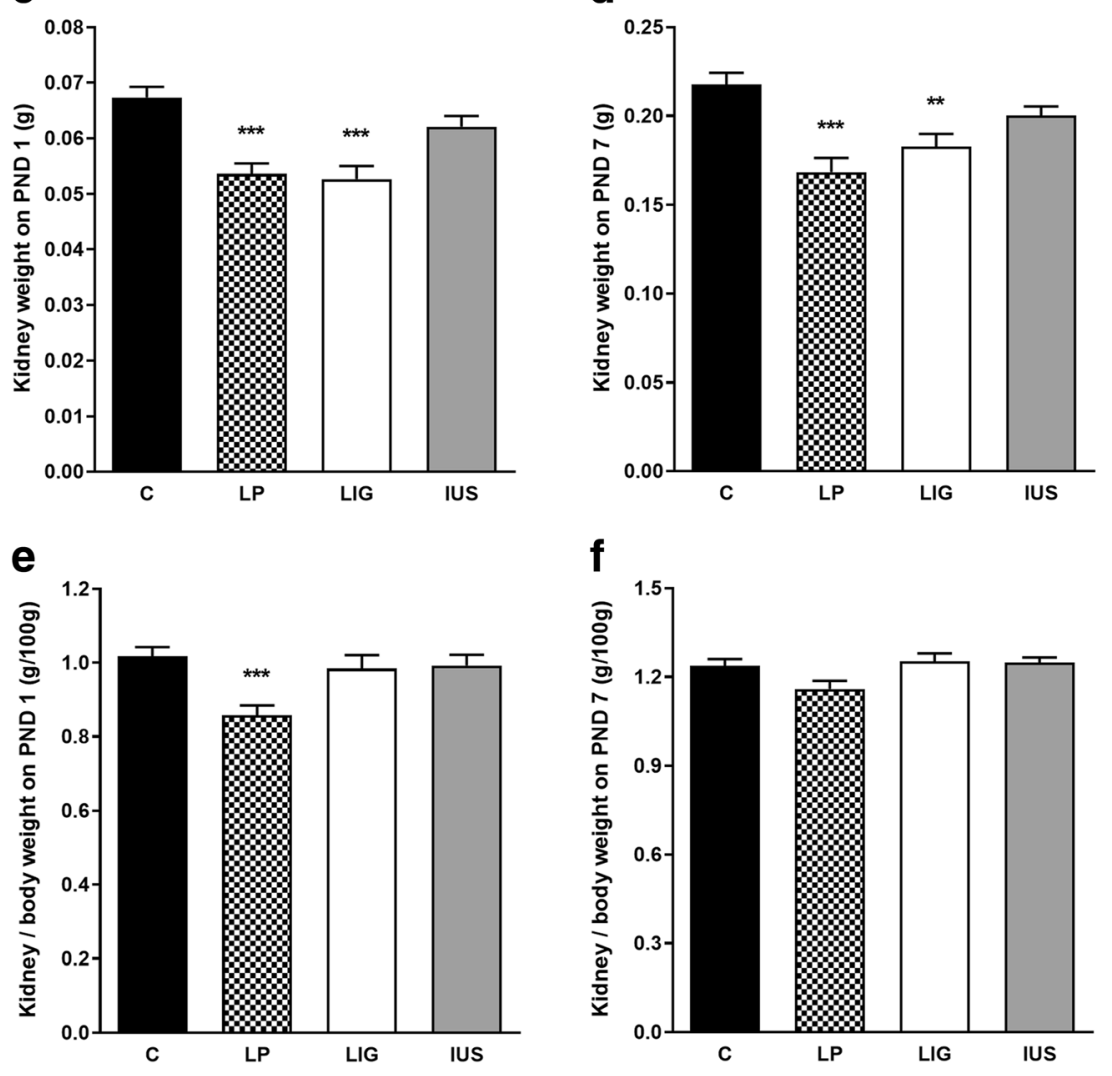

\section{Materials and methods}

\section{Animal model}

All procedures were conducted in accordance with the German regulations and legal requirements. The experimental protocol was approved by the Institutional and Governmental Review Boards (LANUV NRW AZ 84-02.04.2012.A316).

Direct comparison of kidneys during early postnatal life from IUGR offspring after (1) low protein (LP) diet throughout pregnancy $[16,19]$, (2) bilateral uterine vessel ligation (LIG) during terminal pregnancy [16, 17, 24-26], and (3) intrauterine stress (IUS) by sham operation in late pregnancy $[16,17,24-26]$ with a control (C) group offers the unique opportunity to differentiate the molecular details of early kidney programming either after nutritional protein deficiency or reduced uterine blood flow or intrauterine stress. The models have been thoroughly validated in our laboratory with a focus on translational relevance [16, 17, 19, 24-26]. For full details of the animal experiment see Supplemental File 1, for experimental design see Fig. 1. In brief, Wistar rat dams (Janvier Labs, France) were time-mated and fed either a defined diet (C1000, Altromin, Germany) containing $17.6 \%$ protein throughout pregnancy in groups C, LIG, and IUS or a diet containing $8.1 \%$ protein $(\mathrm{C} 1003$, Altromin) in group LP as described before $[16,17,19]$. In LIG dams, bilateral uterine vessel ligation was performed on GD 18. In IUS dams, the suture material was not fixed but removed after identical 

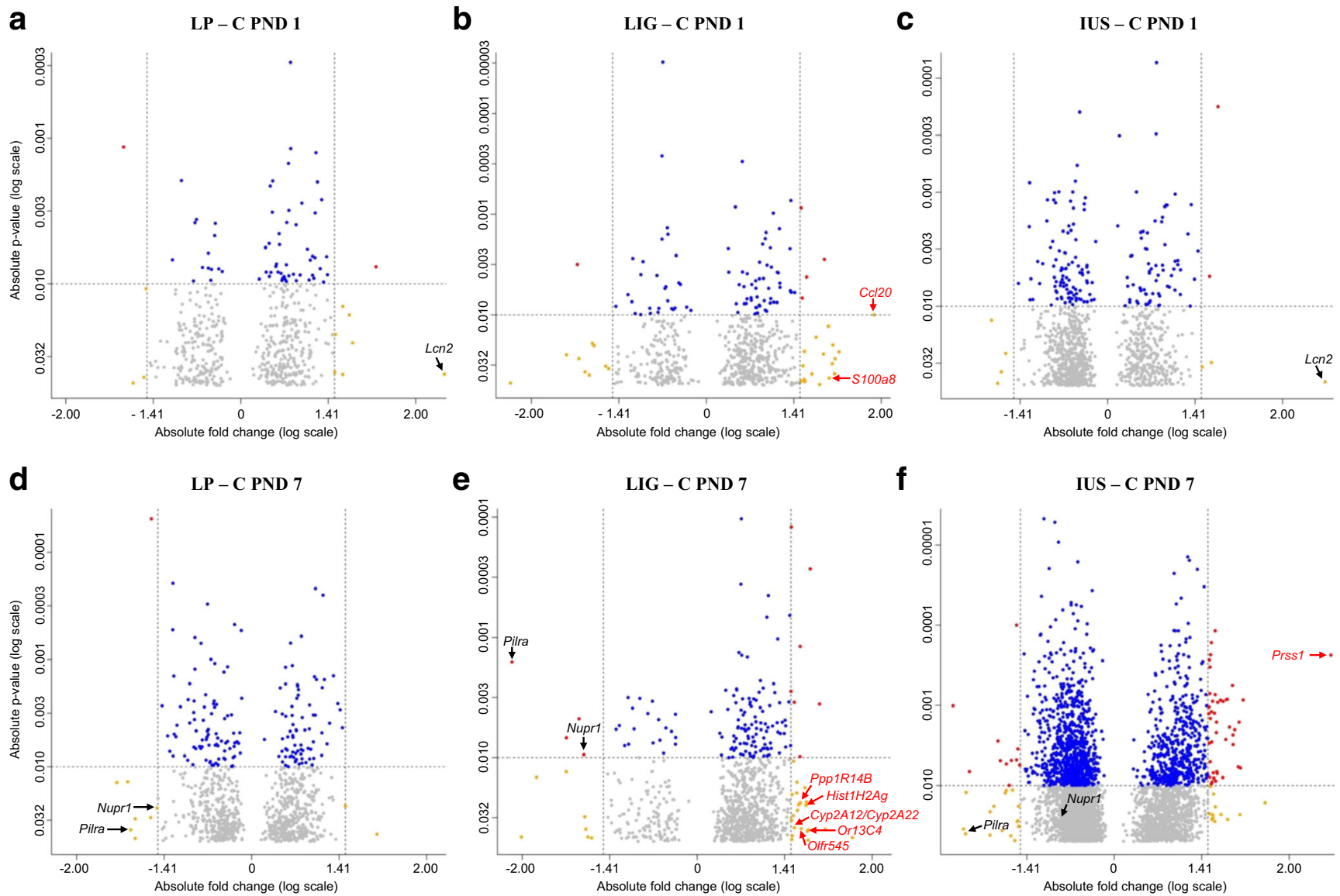

Fig. 3 Volcano plots show all genes differentially expressed $(p<0.05)$ compared with the control group. a Group LP on postnatal day (PND) 1. b LIG on PND 1. c IUS on PND 1. d LP on PND 7. e LIG on PND 7. f IUS on PND 7. Each point represents a gene. Points are differentiated by color depending on fold change (fc) and $p$ value (gray, $\mathrm{fc}<|1.5|$ and

$p<0.05$ but $>0.01$; blue, $\mathrm{fc}<|1.5|$ and $p<0.01$; yellow, $\mathrm{fc} \geq|1.5|$ and $p<0.05$ but $>0.01$; red, $\mathrm{fc} \geq|1.5|$ and $p<0.01$ ). Points labeled with gene symbols in black represent transcripts relevantly altered in at least two IUGR groups, points labeled in red represent model-specific alterations

procedures. All dams delivered spontaneously after approximately 22.5 GDs. All offspring were weighed, measured, and sexed on PND 1. In LIG, only the six smallest pups per litter were selected since especially the fetuses near to the ligation display IUGR [26]. As there is sex-specific transcriptional regulation and male rodents seem to be more susceptible to renal programming than females [27], we focused on male pups in all further analyses. For PND 1 studies, whole kidneys were obtained, weighed, and either shock frozen or dissected longitudinally and processed for paraffin embedding. For PND 7 studies, postnatal environmental conditions were standardized in all groups on the first day of life, because litter size and postnatal nutrition are known to affect the final stages of renal development $[28,29]$. In detail, pups from C, LIG, and IUS dams were transferred to non-operated dams from group $\mathrm{C}$ receiving control diet $(\mathrm{C} 1000$, Altromin) and the size of all foster litters was adjusted to four male and four female pups to ensure similar postnatal nutrition. LP pups (four male, four female) were transferred to LP foster dams as postnatal renal programming effects are in part mediated by altered milk quality in this model [30].

For transcriptome microarray analysis, we randomly selected five male pups representing five different original litters per group with a bodyweight within the range of \pm 1 standard deviation around the mean weight in the respective group.

\section{RNA and protein isolation}

For RNA and protein isolation, the whole kidney was processed using the NucleoSpin® RNA/Protein Kit (Machery-Nagel, Germany) according to the manufacturer. RNA concentrations were determined spectrophotometrically, and sample quality was ensured by RNA integrity number measurements.

\section{Statistics and microarray analysis}

Weight data were tested for normal distribution and, thereafter, by Grubb's test for single outliers. Afterwards, Kruskal-Wallis tests were performed as global tests for comparison of data of all four groups. In case of significance $(p<0.05)$, we performed MannWhitney tests as post-hoc tests for all possible group comparisons (LP-C, LIG-C, IUS-C, LP-LIG, LP-IUS, LIG-IUS). Protein 
Fig. 4 Heat map of relevantly altered transcripts (i.e., $p$ value $<$ 0.05 and $\mathrm{fc} \geq|1.5|$ in at least one of the comparisons LP-C, LIG$\mathrm{C}$, and/or IUS-C as indicated by an asterisk) on PND 1. Data is shown for all possible group comparisons. The color intensity indicates the fold changes of the respective transcripts. Red indicates transcript up-regulation, blue indicates down-regulation

Len2
Or6c74
Gzmb
Olfr346
Obp2a
Olfr380
Clca3a1/3a2
Olfr1328
Keg1
Or8a1
Bhmt
Krtap1-5
Ccl20
Gm5416
Fto
Stfa2/211
Or2a14
Or5m10
S100a8
Or51f1
Mmp8
Olfr1373
Ifit3
Olfr849
Ins1
C7
Krtap4-3
Olfr1448
S100a9
Ren
Olfr290/291
Lalba
Slc25a39
Gng7
Gpatch11
Upk3a
Olfr118/120
Hpd
Pdhb
Kmo
Galnt3
Hogd
Upb1
Acsm1
Kap
Or1a1
Cpa3
Sap18

Stard3

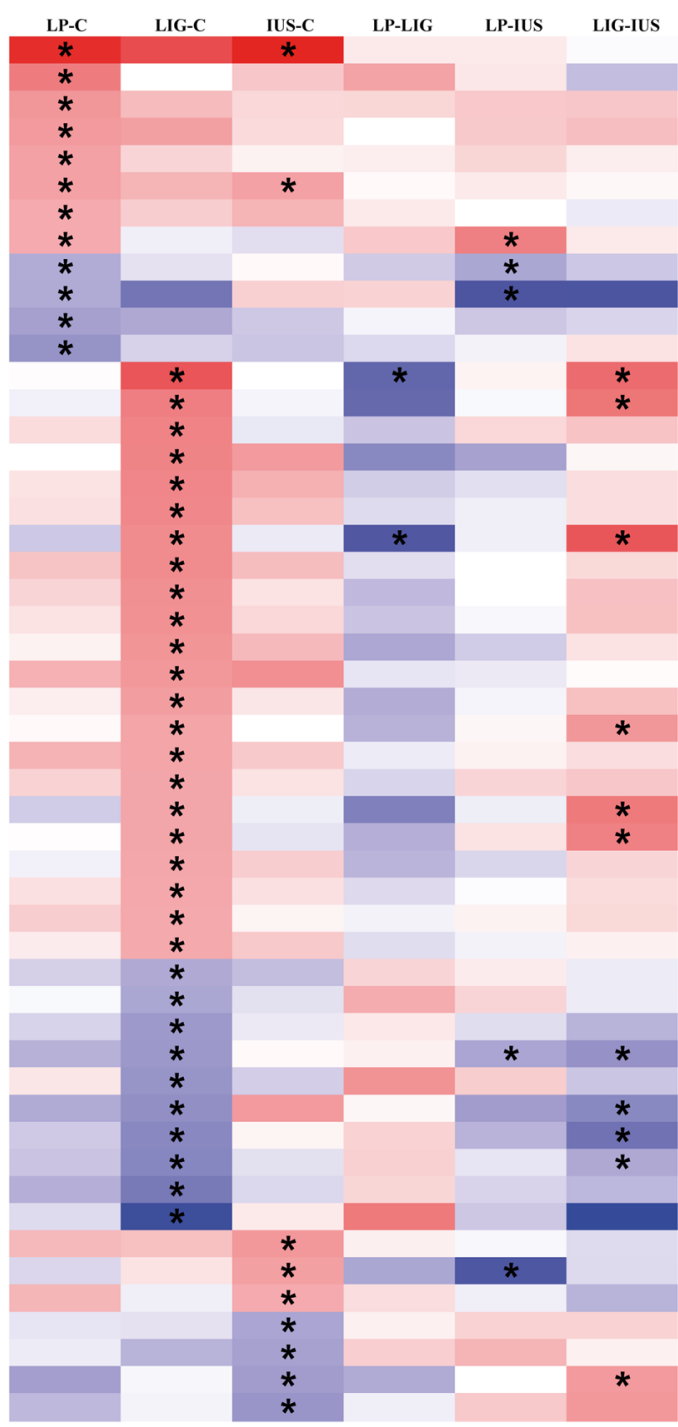

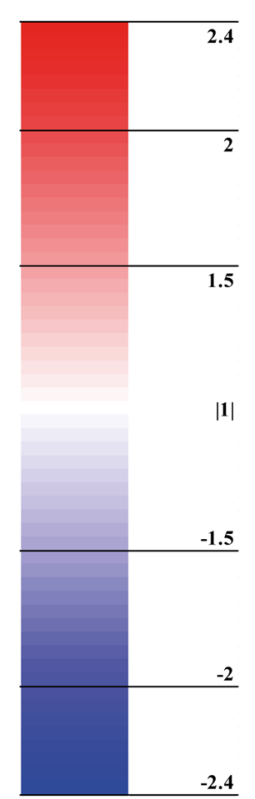

and histological data were analyzed similarly. Statistical analyses were performed using GraphPad Prism 6 (GraphPad Software, La Jolla, CA, USA). All data are shown as mean \pm SEM.

Whole-genome expression array (Affymetrix rat gene 2.0 ST) was performed in cooperation with the Cologne Center for Genomics (CCG, Cologne, Germany). Data were processed by bioinformatics (Atlas Biolabs, Berlin, Germany) to define signal strength for each transcript in each sample and the array quality. For original gene expression lists, please see NCBI Gene Expression Omnibus (GEO) archive GSE107847. Micro-RNAs were digitally excluded from further analyses, since the RNA/Protein Kit does not extract micro-RNAs. Then, datasets of fold change and $p$ values were generated for all possible group comparisons for every single transcript each on PNDs 1 and 7. Next, we performed four steps of transcript data analysis (step 1-4).

Step 1: Principal component analyses were calculated for the whole dataset (GeneSpring GX v. 13.1, Agilent Technologies) as well as for the datasets on PNDs 1 and 7 separately to evaluate whether overall transcripts differ between developmental stages and/or the groups at the same developmental stage. Then, we identified relevantly altered single protein-coding transcripts in the IUGR groups by generating lists of transcripts with a $p$ value $<0.05$ and a fold change $\geq|1.5|$ in the comparisons $\mathrm{LP}-\mathrm{C}$, $\mathrm{LIG}-\mathrm{C}$, and/or IUS-C both on PND 1 and 7. We did not perform Bonferroni adjustment of transcript data $p$ values, because detection of perinatal programming proceedings needs a more subtle and sophisticated approach for identification of relevant alterations compared with cancer or damage models. Volcano plots were created using RStudio (3.5.0) for an overview of transcriptional alterations. Heatmaps were generated, results of the comparisons LP-LIG, LP-IUS, and LIGIUS included in the heatmaps, and all relevant alterations labeled by asterisks. To identify common transcriptional alterations in the IUGR groups, we used the heatmaps to find transcripts which were relevantly altered in all three or at least two 
Fig. 5 Heat map of relevantly altered transcripts (i.e., $p$ value $<$ 0.05 and $\mathrm{fc} \geq|1.5|$ in at least one of the comparisons LP-C, LIG$\mathrm{C}$, and/or IUS-C as indicated by an asterisk) on PND 7. Data is shown for all possible group comparisons. The color intensity indicates the fold changes of the respective transcripts. Red indicates transcript up-regulation, blue indicates down-regulation

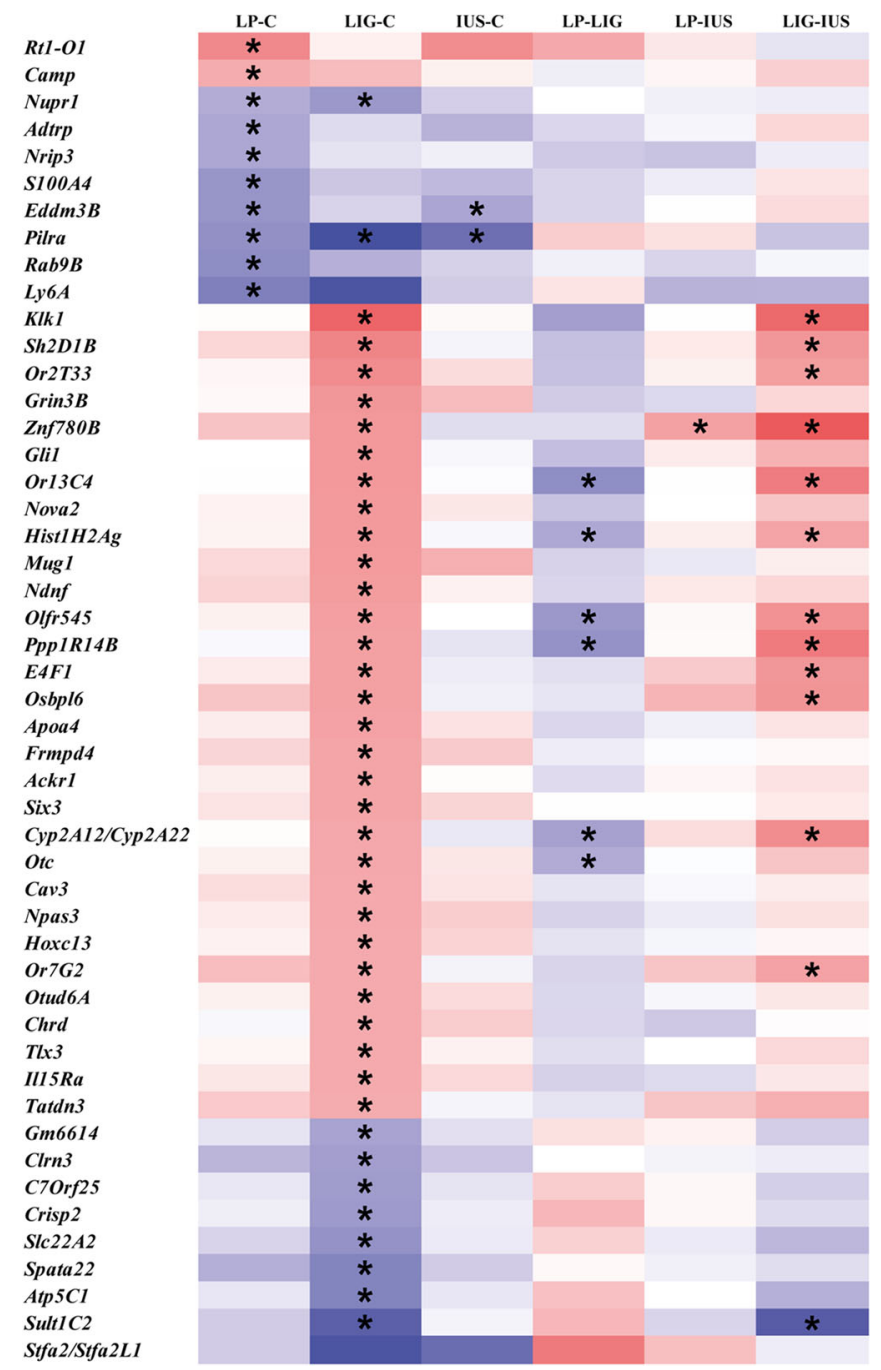

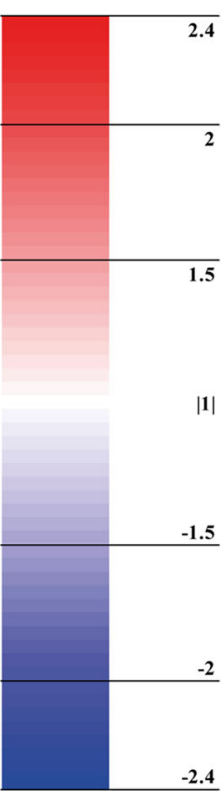

of the comparisons LP-C, LIG-C, IUS-C. Venn diagrams visualizing the number of overlaps between the IUGR groups were also generated. To identify model-specific alterations, we confirmed that the respective transcript was relevantly altered in one group of IUGR pups compared with the control group and in direct comparison with both other groups of IUGR pups as illustrated by the heatmaps.

Step 2: We applied the "kidney filter" provided by Ingenuity Pathway Analysis (IPA) software (http://www. ingenuity.com) on all relevantly altered transcripts. The filter excludes transcripts that do not have known relevance for the kidney in the IPA database. Additionally, we studied the NCBI gene records (http://www.ncbi.nlm.nih.gov/gene) to confirm relevance of each transcript for the kidney.

Step 3: We used the IPA software to identify predicted upstream regulators (cut off $\mathrm{z}$-score $>2$ or $<-2$ and $p$ value $<0.05$ ) based on all transcripts with a $p$ value $<0.05$ (i.e., no fold change cut off was applied). We used this stringent $\mathrm{z}$ score cut off because we wanted to identify relevantly altered predicted upstream regulators only.
Step 4: In case of more than five relevantly altered transcripts or predicted upstream regulators, STRING interaction database analysis was performed to analyze functional enrichments (www.string-db.com, version 11.0 from January 19, 2019) [31]. We applied a false discovery rate (FDR) cut off of $<0.05$ and truncated tables in case of more than 50 significant results in a category to the top 50 results.

\section{Western blots and histology}

To rule out acute severe kidney damage by our experimental setting, we performed western blots of proteins indicative of cellular stress, autophagy, and apoptosis (CHOP, LC3BI/ LC3BII; cleaved PARP/PARP). In order to add relevance to our data, we performed single confirmatory western blots of proteins indicated to be relevant by upstream regulator analyses (RICTOR, HNF4A, CREB). Furthermore, the first data on cellular inflammation was generated by quantification of CD68 positive cells (i.e., monocytes and macrophages) per $\mathrm{mm}^{2}$ kidney area. Western blots and histology were performed 


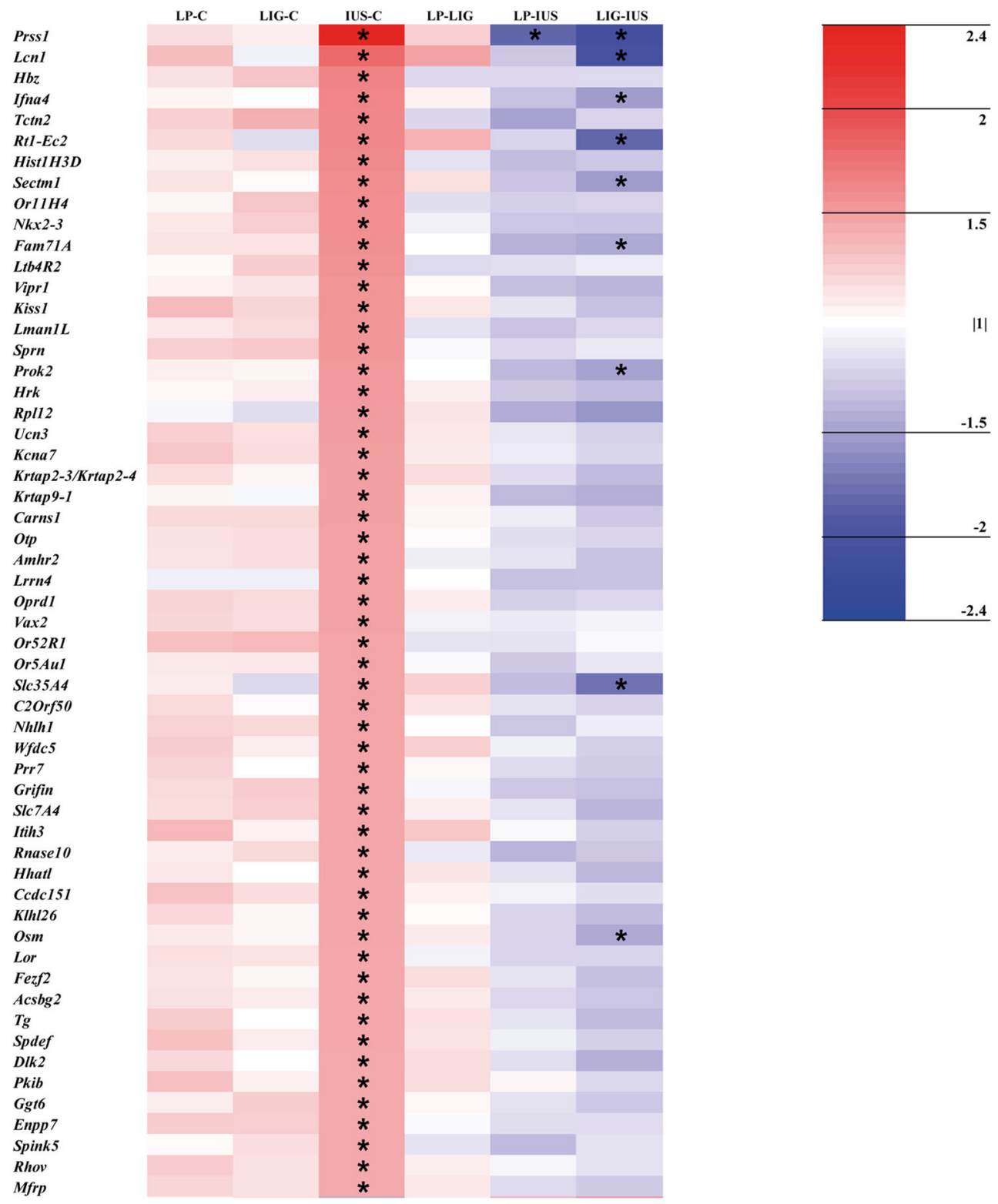

Fig. 5 (continued)

using standard procedures (for details see Supplemental File 2). For antibodies used please see Supplemental Table 1.

\section{Results}

\section{Postnatal absolute kidney weight is reduced after protein malnutrition and utero-placental insufficiency, but relative kidney weight after protein malnutrition only}

Birth weight was significantly reduced in all three groups of IUGR pups (Fig. 2a). On PND 7, bodyweight showed a similar pattern (Fig. 2b). Interestingly, absolute kidney weight was significantly reduced in both LP and LIG animals on
PNDs 1 (Fig. 2c) and 7 (Fig. 2d), but kidney weight in relation to body weight was reduced in LP animals on PND 1 exclusively (Fig. 2e). In IUS animals, neither absolute nor relative kidney weight was significantly altered.

Array data-step 1-principal component analyses, volcano plots, heatmaps, and Venn diagrams indicate only a few common transcriptional alterations after IUGR of different origins

Principal component analyses indicated differences in global transcript expression patterns between PNDs 1 and 7 in all groups (Supplemental Fig. 1A). On PND 7, IUS pups separated from all other groups (including control group C) (Supplemental Fig. 1B). 

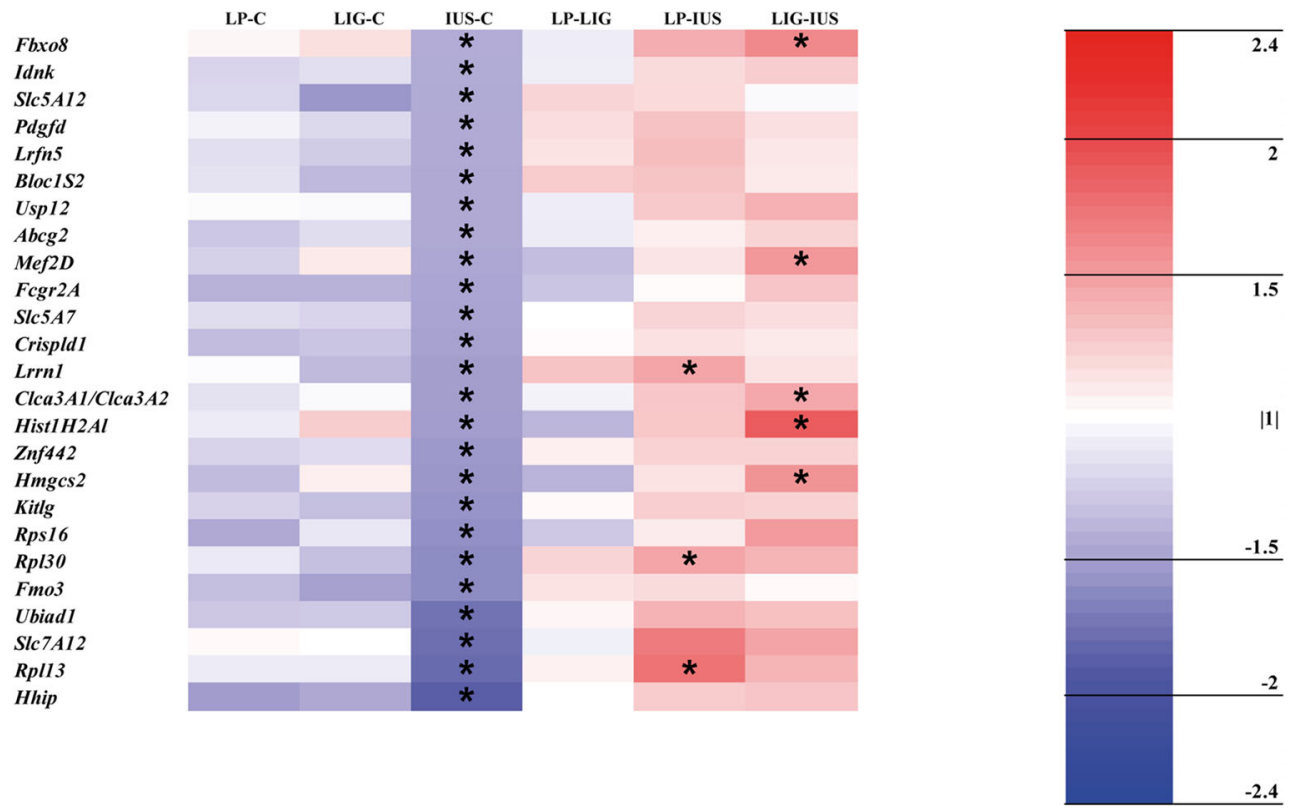

Fig. 5 (continued)

Looking at single transcripts, 53 out of $>27,000$ transcripts (LP, $n=12$; LIG, $n=32$; IUS, $n=9$ ) were relevantly altered on PND 1 (Supplemental Table 2). However, the volcano plots (Fig. 3a, b, and c), heatmap (Fig. 4), and Venn diagram (Supplemental Fig. 2A) did not indicate any common alterations in the three IUGR groups. LP and IUS pups shared an upregulated Lcn 2 transcript, which also was $>2$-fold but not significantly increased in LIG pups. Model-specific transcriptional alterations were identified in LIG pups only ( $n=2$ transcripts; Ccl20 and S100a8). On PND 7, we identified 134 relevantly altered transcripts (LP, $n=10$; LIG, $n=41$; IUS, $n=83$; Supplemental Table 3). Interestingly, the volcano plots (Fig. 3d, e, and f), heatmap (Fig. 5), and Venn diagram (Supplemental Fig. 2B) indicated that the Pilra transcript was reduced in all three groups of IUGR pups. Nupr1 was reduced in LP and LIG pups, and also significantly but $<1.5$-fold reduced in IUS pups. Model-specific transcriptional alterations were identified in LIG ( $n=5$ transcripts) and IUS pups ( $n=1$ transcript).

Looking for overlaps between PND 1 and PND 7, we could not identify any transcript which was relevantly altered in a similar direction. Stfa2/Stfa2L1 was increased in LIG pups on PND 1 and decreased on PND 7.

\section{Array data-step 2-IPA "kidney filter" and NCBI gene records identify transcripts with known relevance in the kidney}

On PND 1, the "kidney filter" provided by IPA to all relevantly altered transcripts identified three transcripts in LP pups (including increased Lcn2), nine in LIG pups (including increased Ren and $C c l 20$ ), and two in IUS pups (including increased Lcn2) (Supplemental Table 4). On PND 7, the "kidney filter" identified three transcripts in LP (including reduced Nupr1), ten in LIG (including reduced Nupr1), and 15 in IUS pups (including reduced Hhip; Supplemental Table 5). NCBI gene records confirmed the results generated by the IPA "kidney filter."

\section{Array data-step 3-upstream regulator analysis predicts a regulatory response in LIG pups predominantly on PND 1, but in LP and IUS pups predominantly on PND 7}

On PND 1, IPA predicted relevantly altered upstream regulators predominantly in the kidneys of LIG pups, including many activated key regulators of inflammation (e.g., NFKB1, CREB1, TNF, IL1B, TLRs, MYD88; Supplemental Table 6). Inhibited IL10RA was predicted for both LIG and IUS pups. On PND 7, relevantly altered upstream regulators were mainly predicted in LP and IUS pups. Activation of RICTOR and KDM5A as well as inhibition of NRF1, NFE2L2, LHX1, HTT, and HNF4A were predicted for both groups. Additional predicted alterations in LP pups included inhibition of the anti-inflammatory metabolic regulators PPARA, PPARG, and INSR. Looking for overlaps between PND 1 and 7, HNF4A inhibition was predicted in LP pups at both time points (Supplemental Table 7).

Array data-step 4-STRING analysis unveils association of molecular alterations to inflammation and lipid metabolism in LIG pups on PND 1 and in LP pups on PND 7

On the level of relevantly altered transcripts, functional enrichment analyses hinted at arachidonic acid-binding and 
neutrophil aggregation in LIG pups on PND 1 (Supplemental Table 8), whereas there were no significant enrichments in IUS and LP pups. On PND 7, there were no enrichments of relevantly altered transcripts at all.

On the level of relevantly altered predicted upstream regulators, functional enrichments hinted at inflammation and immuneresponse-regulating processes in LIG pups on PND 1 (Supplemental Table 9). On PND 7, there was evidence for inhibited AMPK and PPAR signaling, inhibited transcription and inhibited steroid-related metabolism in LP pups (Supplemental Table 10) as well as altered transcriptional regulation and metabolic processes in IUS pups (Supplemental Table 11).

\section{Confirmatory tests on the protein level demonstrate postnatal dysregulation of RICTOR in the kidneys of LP and LIG pups}

We found no evidence for ER-stress, apoptosis, and autophagy since there was neither a significant regulation of CHOP and cleaved PARP/PARP ratios nor significant alterations in LC3BII/ LC3BI ratios (Fig. 6). Interestingly, RICTOR protein expression (Fig. 7) was significantly increased in LP pups compared with $\mathrm{C}$ pups on PND 7, confirming the prediction made by upstream regulator analysis before. In LIG, pups compared with both C and LP pups, RICTOR was significantly increased on PND 1, which had not been predicted. In IUS pups, prediction of increased RICTOR on PND 7 could not be verified. Moreover, predicted alterations of neither HNF4A nor CREB proteins could be verified on the protein level (Fig. 7). For a summary of western blot results see Table 1. CD68 immunohistochemistry did not show significant results on PND 1 and PND 7 (Supplemental Fig. 3).

\section{Discussion}

Chronic kidney disease has become a global health burden affecting up to $10 \%$ of the population [32]. Adverse intrauterine and early childhood conditions are common all over the world $[2,4]$ and have been recognized as predisposing factors [6, 9]. Here, we performed a transcriptome analysis in IUGR rats during and at the end of nephrogenesis to identify transcriptional alterations, predict dysregulated functional networks, and generate hypotheses which molecules or networks may contribute
Fig. 6 Western blot analyses of a renal microtubule-associated protein $1 \mathrm{~A} / \mathrm{B}$ light chain $3 \mathrm{~B}$ I and II (LC3B I and LC3B II), b CCAA T-enhancer-binding protein homologous protein (CHOP), and $\mathbf{c}$ Poly [ADP-ribose] polymerase (PARP and cleaved PARP) are shown on postnatal days (PND) 1 and 7 each. Glyceraldehyde 3phosphate dehydrogenase (GAPDH) was used as reference protein. Ratios were calculated for LC3B II/LC3B I,

$\mathrm{CHOP} / \mathrm{GAPDH}$, and cleaved PARP/PARP, respectively, and are shown for each group $(\mathrm{C}$, controls; LP, low protein; LIG, ligation; IUS, intrauterine stress) as mean \pm SEM directly below the appropriate western blot signals; N/A, not applicable because there was no cleaved PARP signal available. There were no significant differences between the groups

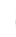

a

$\begin{array}{ll}\text { Postnatal day } & \text { Group } \\ \text { PND1 } & \text { LC3B I (16 kDa) } \\ & \text { LC3B II (14 kDa) } \\ & \text { GAPDH (37 kDa) } \\ & \text { Ratio (LC3B II/I) } \\ \text { PND7 } & \text { LC3B I (16 kDa) } \\ & \text { LC3B II (14 kDa) } \\ & \text { GAPDH (37 kDa) } \\ & \text { Ratio (LC3B II/I) }\end{array}$
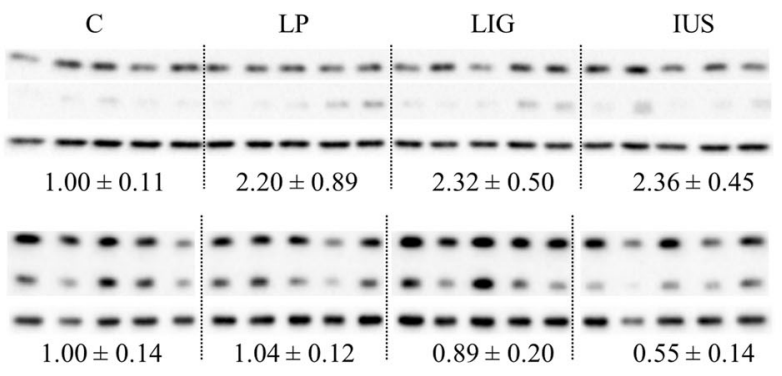

b

PND1

Group CHOP (29 kDa) GAPDH (37 kDa) Ratio

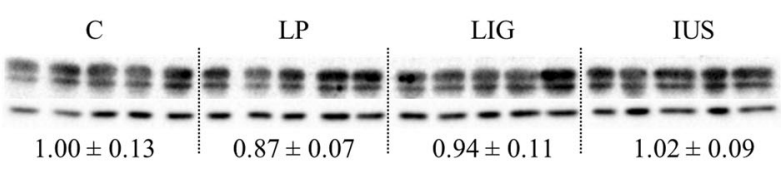

PND7

CHOP (29 kDa) GAPDH (37 kDa) Ratio

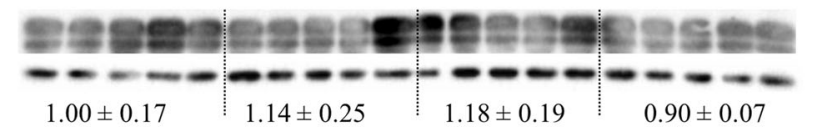

C

PND1

PARP (116 kDa) CPARP (89 kDa) GAPDH (37 kDa) Ratio (cP./P.)

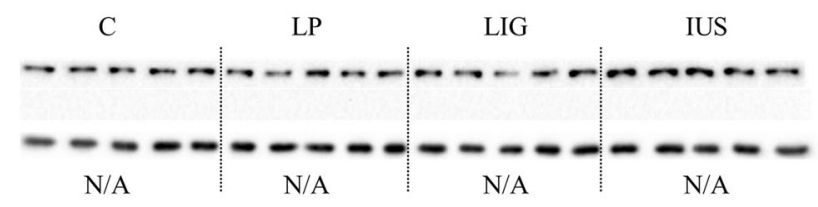

PND7
PARP (116 kDa) cPARP $(89 \mathrm{kDa})$ GAPDH (37 kDa) Ratio (cP./P.)

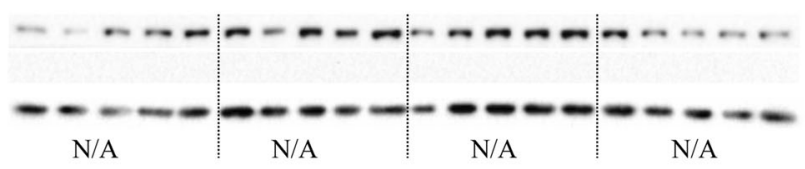


to adverse developmental kidney programming. Significant acute kidney damage was ruled out by negative results for protein markers indicative of ER-stress, autophagy, apoptosis, or infiltration with macrophages. Transcriptional alterations were comprehensively analyzed by whole transcriptome microarrays in thoroughly validated animal models covering different origins of IUGR and optimized for direct comparison. As only $40-50 \%$ of the variation in protein concentration can be explained by changes in gene expression, we performed single confirmatory tests (western blots, immunohistochemistry) to add evidence to our hypotheses [33].

At first view, more differences than similarities exist between the IUGR groups. As indicated by different phenotypes, LIG pups have an adequate kidney/body weight ratio at birth and may show permanently reduced absolute kidney size [24], whereas LP pups have decreased kidney/body weight ratio at birth and apparently show catch-up kidney weight gain after the completion of nephrogenesis [19]. LIG offspring showed a 3-fold higher number of early transcriptional dysregulations and IUS offspring a 2to 8-fold higher number at the later time point compared with the other IUGR groups. Besides, volcano plots, heatmaps, and Venn diagrams indicated more model-specific than overlapping transcriptional alterations. However, principal component analyses indicated that above all, the developmental stage determines global transcription patterns in postnatal rat kidneys [34]. IUGR obviously has more subtle effects that are not strong enough to be identified by principal component analyses. Also, despite differing alterations on the level of single transcripts, similar biological processes may be affected in all IUGR groups.

Indeed, there is evidence for dysregulation of inflammatory processes in all three groups of IUGR pups. On PND7, reduced transcription of the paired immunoglobin-like type 2 receptor alpha (Pilra) in all groups of IUGR pups and of the nuclear transcriptional regulator protein 1 (Nuprl) in LP and LIG pups suggest increased susceptibility to monocyte infiltration and tissue remodeling $[35,36]$ at the end of nephrogenesis. Moreover, model-specific alterations in LIG and IUS animals can also be linked to inflammation. Thus, transcriptional upregulations of C-C motif chemokine 20 (Ccl20) and S100a8/a9 (encoding calprotectin) as well as inhibition of the kidney androgen-regulated protein (Kap) transcript were identified in LIG pups at PND 1. CCL20 is a chemotactic factor that may aggravate renal inflammation [37]. Increased S100a8/a9 and decreased Kap further suggest increased susceptibility to inflammation [38, 39]. Subsequent functional enrichment analysis yielded in arachidonic acid-binding and neutrophil aggregation; analysis of predicted upstream regulators (i.e., molecules which may explain transcriptional alterations) indicated functional enrichments in toll-like-receptor, NF-kappa B, and TNF
Fig. 7 Western blot analyses of a RICTOR (upper part of figure), $\mathbf{b}$ hepatic nuclear factor 4 alpha (HNF4A; medium part of figure), and $\mathbf{c}$ renal cAMP responsive element binding protein (CREB; lower part of figure) are shown on postnatal day (PND) 1 and PND 7 each. Glyceraldehyde 3phosphate dehydrogenase (GAPDH) was used as reference protein. Ratios were calculated for RICTOR/GAPDH, HNF4A/ GAPDH, and phosphoCREB/ CREB, respectively, and are shown for each group $(\mathrm{C}$, controls; LP, low protein; LIG, ligation; IUS, intrauterine stress) as mean \pm SEM directly below the appropriate western blot signals; $*$, significant $(p<0.05)$ difference compared with the control group. Further comparisons with significant results: PND 1, RICTOR LP-LIG, *; PND 7, none PND1

Rictor (200kDa) GAPDH (37 kDa) Ratio

PND7

Rictor (200kDa) GAPDH (37 kDa) Ratio

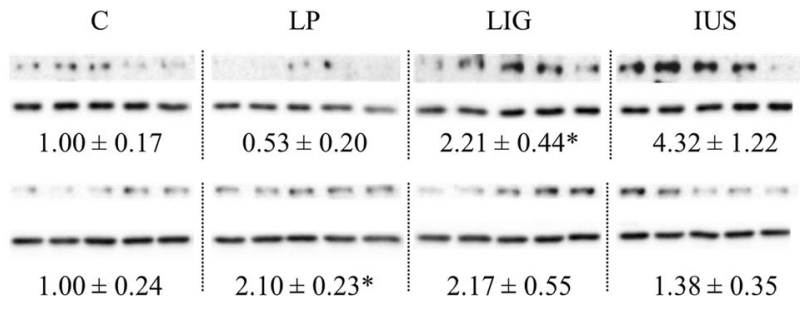

b

PND1

Group

HNF4A (53kDa) GAPDH (37 kDa) Ratio

PND7

HNF4A (53kDa) GAPDH (37 kDa) Ratio
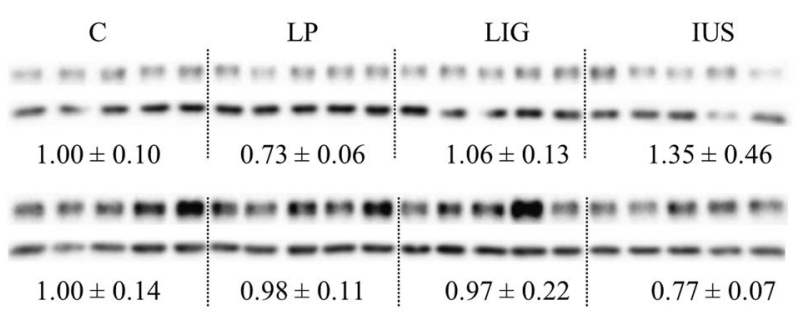

C PND1

Group pCREB (43 kDa) CREB (43 kDa) GAPDH (37 kDa) Ratio (pCR./CR.)

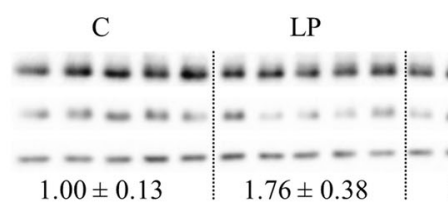

LIG

IUS

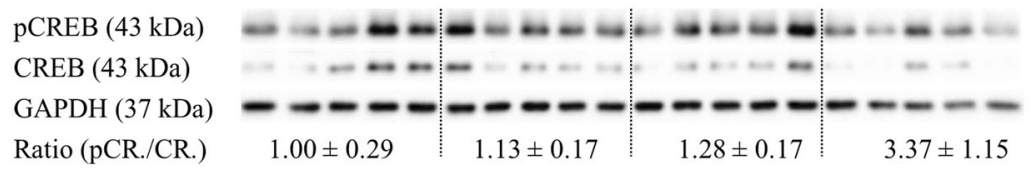


Table 1 Summary of western blot results is shown for six different group comparisons

\begin{tabular}{llllllll}
\hline Molecule & Time & $\begin{array}{l}\text { LP- } \\
\text { C }\end{array}$ & $\begin{array}{l}\text { LIG- } \\
\text { C }\end{array}$ & $\begin{array}{l}\text { IUS- } \\
\text { C }\end{array}$ & $\begin{array}{l}\text { LP- } \\
\text { LIG }\end{array}$ & $\begin{array}{l}\text { LP- } \\
\text { IUS }\end{array}$ & $\begin{array}{l}\text { LIG- } \\
\text { IUS }\end{array}$ \\
\hline LC3BI/LC3BII & PND 1 & $=$ & $=$ & $=$ & $=$ & $=$ & $=$ \\
& PND 7 & $=$ & $=$ & $=$ & $=$ & $=$ & $=$ \\
CHOP & PND 1 & $=$ & $=$ & $=$ & $=$ & $=$ & $=$ \\
& PND 7 & $=$ & $=$ & $=$ & $=$ & $=$ & $=$ \\
Cleaved PARP/PARP & PND 1 & N/A & N/A & N/A & N/A & N/A & N/A \\
& PND 7 & N/A & N/A & N/A & N/A & N/A & N/A \\
RICTOR & PND 1 & $=$ & $\uparrow$ & $=$ & $\downarrow$ & $=$ & $=$ \\
& PND 7 & $\uparrow$ & $=$ & $=$ & $=$ & $=$ & $=$ \\
HNF4 $\alpha$ & PND 1 & $=$ & $=$ & $=$ & $=$ & $=$ & $=$ \\
& PND 7 & $=$ & $=$ & $=$ & $=$ & $=$ & $=$ \\
PhosphoCREB/CREB & PND 1 & $=$ & $=$ & $=$ & $=$ & $=$ & $=$ \\
& PND 7 & $=$ & $=$ & $=$ & $=$ & $=$ & $=$ \\
\hline
\end{tabular}

$\uparrow$, significant $(p<0.05)$ increase; $\downarrow$, significant reduction; =, no significance; $N / A$, not applicable; $L C 3 B$, microtubule-associated proteins $1 \mathrm{~A} / 1 \mathrm{~B}$ light chain 3B; $C H O P$, CCAAT-enhancer-binding protein homologous protein; PARP, poly [ADP-ribose] polymerase; $C R E B$, cAMP responsive element binding protein; $H N F 4 \alpha$, hepatocyte nuclear factor 4 alpha signaling. In IUS pups, increased transcription of interferon-alpha 4 (Ifna4) and leukotriene B4 receptor 2 (Ltb4r2) on PND 7 further hinted at dysregulation of inflammatory processes. LTB4R2 is a cell surface receptor that can bind several arachidonic acid metabolites and has stimulatory effects on neutrophils [40]. Further research is needed to clarify how group-specific transcriptional alterations during early and/or late nephrogenesis which can all be linked to dysregulation of inflammation may result in similarly elevated risk of aggravated course of glomerulonephritis in later life $[19,24]$. Since it is known that earlylife conditions affect arachidonic acid content in kidney cell membranes [41], this could be an important longterm mediator of susceptibility towards inflammation [42].

Beyond inflammation, we identified further common and/or group-specific molecular dysregulations during kidney development after IUGR. Dysregulation of AMPK and PPAR signaling pathways as suggested by enrichment analysis of predicted upstream regulators in LP pups on PND 7 is of interest, since this may increase the susceptibility towards obesity-associated kidney damage [43]. PPARs have blood pressure lowering and antiinflammatory properties, and renal PPAR dysregulation has been linked to programmed hypertension and inflammation [44]. Dysregulation of RICTOR in LP pups on PND7 and in LIG pups on PND1 indicates that mTORrelated processes may be important modulators of kidney programming $[45,46]$. Single transcriptional alterations of interest concerning renal programming include upregulation of Ren (encoding RENIN) in LIG and reduction of hedgehog interacting protein (Hhip) in IUS pups, both of which are known to be essential during kidney development [47, 48].

Our study has some methodological limitations. First, we did not perform full Bonferroni adjustment of array data. Detection of perinatal programming proceedings, however, probably needs a more subtle and sophisticated approach for gene and network identification since the expected range of change in gene expression is less pronounced than in cancer or damage models. Second, array probe identifications and the IPA database are continuously refined. Last, we had to use total kidneys for our measurements, potentially masking tissue compartment-specific alterations.

In summary, dysregulation of inflammation-related pathways could be a "common" molecular feature of renal programming after IUGR of different origins although there are group- and time point-specific differences on the single transcript level. RICTOR could be a common modulator of renal programming in LP and LIG pups. Metabolic dysregulation affecting PPAR and AMPK signaling could be an insultspecific modulator of renal programming in LP pups. Based on our data, we plan to develop specific interventions to ameliorate programmed kidney disease.

Acknowledgements Open Access funding provided by Projekt DEAL.

Author contributions Study concept and design: E.N., G.F., K.-D.N.; methodology and acquisition of data: E.N., F.L., G.F., J.V., M.W., L.S., N.M., K.-D.N.; data analysis: E.N., F.L., G.F., J.V., M.C.L., B.B., K.D.N.; drafting of the manuscript: E.N., F.L., G.F., J.V., K.-D.N.; validation and revision of the manuscript: E.N., F.L., G.F., J.V., M.W., L.S., N.M., L.T.W., M.C.L., B.B., J.D., K.-D.N.; statistical analysis: E.N., F.L., G.F., J.V., K.-D.N.; funding acquisition: E.N., K.-D.N. 
Funding information The study was supported by the German Research Foundation (DGF grant no. NU-137/3-1 to KDN and EN).

\section{Compliance with ethical standards}

Conflict of interest The authors declare that they have no conflict of interest.

Open Access This article is licensed under a Creative Commons Attribution 4.0 International License, which permits use, sharing, adaptation, distribution and reproduction in any medium or format, as long as you give appropriate credit to the original author(s) and the source, provide a link to the Creative Commons licence, and indicate if changes were made. The images or other third party material in this article are included in the article's Creative Commons licence, unless indicated otherwise in a credit line to the material. If material is not included in the article's Creative Commons licence and your intended use is not permitted by statutory regulation or exceeds the permitted use, you will need to obtain permission directly from the copyright holder. To view a copy of this licence, visit http://creativecommons.org/licenses/by/4.0/.

\section{References}

1. Ravelli GP, Stein ZA, Susser MW (1976) Obesity in young men after famine exposure in utero and early infancy. N Engl J Med 295(7):349-353

2. UNICEF-WHO (2019) Low birthweight estimates: levels and trends 2000-2015. WHO reference number: WHO/NMH/NHD/ 1921

3. Nüsken E, Turnwald EM, Fink G, Voggel J, Yosy C, Kretschmer T, Handwerk M, Wohlfarth M, Weber LT, Hucklenbruch-Rother E, Dötsch J, Nüsken KD, Appel S (2019) Maternal high fat diet and in-utero metformin exposure significantly impact upon the fetal renal proteome of male mice. J Clin Med 8 (5)

4. Blencowe H, Krasevec J, de Onis M, Black RE, An X, Stevens GA, Borghi E, Hayashi C, Estevez D, Cegolon L, Shiekh S, Ponce Hardy V, Lawn JE, Cousens S (2019) National, regional, and worldwide estimates of low birthweight in 2015, with trends from 2000: a systematic analysis. Lancet Glob Health. https://doi.org/10. 1016/S2214-109X(18)30565-5

5. Baschat AA (2004) Pathophysiology of fetal growth restriction: implications for diagnosis and surveillance. Obstet Gynecol Surv 59(8):617-627

6. Vikse BE, Irgens LM, Leivestad T, Hallan S, Iversen BM (2008) Low birth weight increases risk for end-stage renal disease. J Am Soc Nephrol 19(1):151-157

7. Nüsken E, Dötsch J, Weber LT, Nüsken KD (2018) Developmental programming of renal function and re-programming approaches. Front Pediatr 6:36

8. Abitbol CL, Moxey-Mims M (2016) Chronic kidney disease: low birth weight and the global burden of kidney disease. Nat Rev Nephrol 12(4):199-200

9. Hallan S, Euser AM, Irgens LM, Finken MJ, Holmen J, Dekker FW (2008) Effect of intrauterine growth restriction on kidney function at young adult age: the Nord Trondelag Health (HUNT 2) Study. Am J Kidney Dis 51(1):10-20

10. Ruggajo P, Svarstad E, Leh S, Marti HP, Reisaether AV, Vikse BE (2016) Low birth weight and risk of progression to end stage renal disease in IgA nephropathy-a retrospective registry-based cohort study. PLoS One 11(4):e0153819

11. Teeninga N, Schreuder MF, Bokenkamp A, Delemarre-van de Waal HA, van Wijk JA (2008) Influence of low birth weight on minimal change nephrotic syndrome in children, including a meta-analysis. Nephrol Dial Transplant 23(5):1615-1620

12. Zandi-Nejad K, Luyckx VA, Brenner BM (2006) Adult hypertension and kidney disease: the role of fetal programming. Hypertension 47(3):502-508

13. Challen G, Gardiner B, Caruana G, Kostoulias X, Martinez G, Crowe M, Taylor DF, Bertram J, Little M, Grimmond SM (2005) Temporal and spatial transcriptional programs in murine kidney development. Physiol Genomics 23(2):159-171

14. Quigley R (2012) Developmental changes in renal function. Curr Opin Pediatr 24(2):184-190

15. Schreuder MF, Nyengaard JR, Remmers F, van Wijk JA, Delemarre-van de Waal HA (2006) Postnatal food restriction in the rat as a model for a low nephron endowment. Am J Physiol Ren Physiol 291(5):F1104-F1107

16. Nüsken KD, Schneider H, Plank C, Trollmann R, Nüsken E, Rascher W, Dötsch J (2011) Fetal programming of gene expression in growth-restricted rats depends on the cause of low birth weight. Endocrinology 152(4):1327-1335

17. Nüsken E, Wohlfarth M, Lippach G, Rauh M, Schneider H, Dötsch J, Nüsken KD (2016) Reduced perinatal leptin availability may contribute to adverse metabolic programming in a rat model of uteroplacental insufficiency. Endocrinology 157(5):1813-1825

18. Schreuder MF, Nyengaard JR, Fodor M, van Wijk JA, Delemarrevan de Waal HA (2005) Glomerular number and function are influenced by spontaneous and induced low birth weight in rats. J Am Soc Nephrol 16(10):2913-2919

19. Plank C, Östreicher I, Hartner A, Marek I, Struwe FG, Amann K, Hilgers KF, Rascher W, Dötsch J (2006) Intrauterine growth retardation aggravates the course of acute mesangioproliferative glomerulonephritis in the rat. Kidney Int 70(11):1974-1982

20. Victora CG, Adair L, Fall C, Hallal PC, Martorell R, Richter L, Sachdev HS, Maternal, Child Undernutrition Study G (2008) Maternal and child undernutrition: consequences for adult health and human capital. Lancet 371(9609):340-357

21. Woods LL, Weeks DA, Rasch R (2004) Programming of adult blood pressure by maternal protein restriction: role of nephrogenesis. Kidney Int 65(4):1339-1348

22. Woods LL, Ingelfinger JR, Nyengaard JR, Rasch R (2001) Maternal protein restriction suppresses the newborn reninangiotensin system and programs adult hypertension in rats. Pediatr Res 49(4):460-467

23. Alexander BT (2003) Placental insufficiency leads to development of hypertension in growth-restricted offspring. Hypertension 41(3): 457-462

24. Plank C, Nüsken K-D, Menendez-Castro C, Hartner A, Östreicher I, Amann K, Baumann P, Peters H, Rascher W, Dötsch J (2010) Intrauterine growth restriction following ligation of the uterine arteries leads to more severe glomerulosclerosis after mesangioproliferative glomerulonephritis in the offspring. Am J Nephrol 32(4):287-295

25. Nüsken KD, Dötsch J, Rauh M, Rascher W, Schneider H (2008) Uteroplacental insufficiency after bilateral uterine artery ligation in the rat: impact on postnatal glucose and lipid metabolism and evidence for metabolic programming of the offspring by sham operation. Endocrinology 149(3):1056-1063

26. Nüsken KD, Warnecke C, Hilgers KF, Schneider H (2007) Intrauterine growth after uterine artery ligation in rats: dependence on the fetal position in the uterine horn and need for prenatal marking of the animals. J Hypertens 25(1):247-248

27. Sundrani DP, Roy SS, Jadhav AT, Joshi SR (2017) Sex-specific differences and developmental programming for diseases in later life. Reprod Fertil Dev 29(11):2085-2099

28. Briffa JF, O'Dowd R, Moritz KM, Romano T, Jedwab LR, McAinch AJ, Hryciw DH, Wlodek ME (2017) Uteroplacental insufficiency reduces rat plasma leptin concentrations and alters 
placental leptin transporters: ameliorated with enhanced milk intake and nutrition. J Physiol 595(11):3389-3407

29. Wlodek ME, Westcott K, Siebel AL, Owens JA, Moritz KM (2008) Growth restriction before or after birth reduces nephron number and increases blood pressure in male rats. Kidney Int 74(2):187-195

30. Martin Agnoux A, Antignac JP, Boquien CY, David A, Desnots E, Ferchaud-Roucher V, Darmaun D, Parnet P, Alexandre-Gouabau MC (2015) Perinatal protein restriction affects milk free amino acid and fatty acid profile in lactating rats: potential role on pup growth and metabolic status. J Nutr Biochem 26(7):784-795

31. Szklarczyk D, Morris JH, Cook H, Kuhn M, Wyder S, Simonovic M, Santos A, Doncheva NT, Roth A, Bork P, Jensen LJ, von Mering C (2017) The STRING database in 2017: qualitycontrolled protein-protein association networks, made broadly accessible. Nucleic Acids Res 45(D1):D362-D368

32. Eckardt KU, Coresh J, Devuyst O, Johnson RJ, Kottgen A, Levey AS, Levin A (2013) Evolving importance of kidney disease: from subspecialty to global health burden. Lancet 382(9887):158-169

33. Vogel C, Marcotte EM (2012) Insights into the regulation of protein abundance from proteomic and transcriptomic analyses. Nat Rev Genet 13(4):227-232

34. Potter SS, Brunskill EW (2014) Building an atlas of gene expression driving kidney development: pushing the limits of resolution. Pediatr Nephrol 29(4):581-588

35. Galichon P, Bataille A, Vandermeersch S, Wetzstein M, Xu-Dubois YC, Legouis D, Hertig A, Buob D, Placier S, Bige N, Lefevre G, Jouanneau C, Martin C, Iovanna JL, Rondeau E (2017) Stress response gene Nuprl alleviates cyclosporin a nephrotoxicity in vivo. J Am Soc Nephrol 28(2):545-556

36. Kohyama M, Matsuoka S, Shida K, Sugihara F, Aoshi T, Kishida $\mathrm{K}$, Ishii KJ, Arase H (2016) Monocyte infiltration into obese and fibrilized tissues is regulated by PILRalpha. Eur J Immunol 46(5): 1214-1223

37. Krebs CF, Paust HJ, Krohn S, Koyro T, Brix SR, Riedel JH, Bartsch P, Wiech T, Meyer-Schwesinger C, Huang J, Fischer N, Busch P, Mittrucker HW, Steinhoff U, Stockinger B, Perez LG, Wenzel UO, Janneck M, Steinmetz OM, Gagliani N, Stahl RAK, Huber S, Turner JE, Panzer U (2016) Autoimmune renal disease is exacerbated by S1P-receptor-1-dependent intestinal Th17 cell migration to the kidney. Immunity 45(5):1078-1092

38. Pepper RJ, Wang HH, Rajakaruna GK, Papakrivopoulou E, Vogl T, Pusey CD, Cook HT, Salama AD (2015) S100A8/A9 (calprotectin) is critical for development of glomerulonephritis and promotes inflammatory leukocyte-renal cell interactions. Am J Pathol 185(5): 1264-1274

39. de Quixano BB, Villena JA, Aranda M, Brils G, Cuevas A, Hespel T, Lekuona H, Suarez C, Tornavaca O, Meseguer A (2017) Kidney androgen-regulated protein (KAP) transgenic mice are protected against high-fat diet induced metabolic syndrome. Sci Rep 7(1): 16102

40. Yokomizo T (2015) Two distinct leukotriene B4 receptors, BLT1 and BLT2. J Biochem 157(2):65-71

41. Huang YS, Wainwright PE, Redden PR, Mills DE, BulmanFleming B, Horrobin DF (1992) Effect of maternal dietary fats with variable $\mathrm{n}-3 / \mathrm{n}-6$ ratios on tissue fatty acid composition in suckling mice. Lipids 27(2):104-110

42. Ferraro PM, Ferraccioli GF, Gambaro G, Fulignati P, Costanzi S (2009) Combined treatment with renin-angiotensin system blockers and polyunsaturated fatty acids in proteinuric $\operatorname{IgA}$ nephropathy: a randomized controlled trial. Nephrol Dial Transplant 24(1):156160

43. Tsuboi N, Okabayashi Y, Shimizu A, Yokoo T (2017) The renal pathology of obesity. Kidney Int Rep 2(2):251-260

44. D'Agati VD, Chagnac A, de Vries AP, Levi M, Porrini E, HermanEdelstein M, Praga M (2016) Obesity-related glomerulopathy: clinical and pathologic characteristics and pathogenesis. Nat Rev Nephrol 12(8):453-471

45. Li J, Ren J, Liu X, Jiang L, He W, Yuan W, Yang J, Dai C (2015) Rictor/mTORC2 signaling mediates TGFbeta1-induced fibroblast activation and kidney fibrosis. Kidney Int 88(3):515-527

46. Li J, Xu Z, Jiang L, Mao J, Zeng Z, Fang L, He W, Yuan W, Yang J, Dai C (2014) Rictor/mTORC2 protects against cisplatin-induced tubular cell death and acute kidney injury. Kidney Int 86(1):86-102

47. Jensen BL, Stubbe J, Madsen K, Nielsen FT, Skott O (2004) The renin-angiotensin system in kidney development: role of COX-2 and adrenal steroids. Acta Physiol Scand 181(4):549-559

48. Ding H, Zhou D, Hao S, Zhou L, He W, Nie J, Hou FF, Liu Y (2012) Sonic hedgehog signaling mediates epithelial-mesenchymal communication and promotes renal fibrosis. J Am Soc Nephrol 23(5):801-813

Publisher's note Springer Nature remains neutral with regard to jurisdictional claims in published maps and institutional affiliations. 